ALTRUIS, e-ISSN 2620-5513, p-ISSN 2620-5505, Vol. 1, No. 1, April 2018

Abdimas Altruis : Jurnal Pengabdian Kepada Masyarakat

http://e-journal.usd.ac.id/index.php/ABDIMAS

Universitas Sanata Dharma, Yogyakarta

\title{
Lokakarya Kepala Sekolah dan Staf SMK Asji Tentang PPI
}

\author{
Paul Suparno \\ JPMIPA, FKIP, Universitas Sanata Dharma Yogyakarta \\ Email: paulparno@gmail.com \\ https://doi.org/10.24071/altruis.2018.010106
}

\begin{abstract}
The purpose of this workshop was to help ASJI's SMK principals and curriculum staff better understand the Ignatian Pedagogical Paradigm (Paradigma Pedagogi Ignatian -- PPI). The SMK principals and staff were aware that they did not understand enough what PPI was and how to apply PPI in the context of Vocational High Schools (Sekolah Menengah Kejuruan -- SMK). So they wanted to know better and learned more about the PPI spirit, values, and dynamics.To help those principals and staff's needs, ASJI provided a workshop on PPI. A lecturer from Sanata Dharma University was invited to guide the workshop as an instructor. During the workshop, the participants discussed PPI and planned how to apply and improve PPI in their own schools. The result was that every school made one program (RPP) to implement PPI in their schools.
\end{abstract}

Keywords: kepala sekolah, lokakarya, PPI, SMK

\section{PENDAHULUAN}

Kolese-kolese (SMP-SMA) Jesuit yang tergabung dalam ASJI (Asosiasi Sekolah Jesuit Indonesia) telah lama bekerja sama dan mendalami, mengaplikasikan, serta mengembangkan PPI (ParadigmaPedagogi Ignatian) atau yang di Indonesia lebih dikenal dengan nama ParadigmaPedagogi Refleksi (PPR). Salah satu hasil yang mencolok dari kerjasama sekolah-sekolah Jesuit itu adalah penggunaan semangat Ignatian dalam penyelenggaraansekolah-sekolah Jesuit di seluruh Indonesia.

Dalam kerangka kerjasama itu telah dihasilkan berbagai buku pedoman pengelolaan sekolah Jesuit yang digunakan sebagai acuan dalampenyelenggaraan sekolah Jesuit. Ada 4 buku pedoman yang dihasilkan yaitu: (1) Standar Mutu PendidikanSekolah Yesuit; (2) Pedoman Tatakelola Sekolah Yesuit; (3) Kurikulum Berbasis Paradigma Pedagogi Ignatian Sekolah Yesuit; dan (4) Desain Pengembangan Profesionalisme Guru Sekolah Yesuit.

Selain SMP dan SMA, didalam provinsi Jesuit Indonesia ternyata ada 2 sekolah kejuruan yaitu SMK St. Mikael di Surakarta dan SMK PIKA di Semarang. SMK St Mikael menekankan kejuruan teknik mesin, sedangkan SMK PIKA menekankan teknik perkayuan. Selain itu ternyata ada juga beberapa SMK milik Keuskupan Agung Jakarta dan Semarang yang dikelola oleh Jesuit yaitu dalam Perkumpulan Strada di Jakarta dan Yayasan Kanisius di Semarang. Mereka ini ternyata ingin juga menggunakan semangat PPI dalam pengelolaan sekolah mereka dan mereka ingin mendalami semangat itu.

Maka oleh ASJI disadari pentingnya mengadakan lokakarya/workshop untuk membantu mereka ini memahami, mendalami dan nantinya mengaplikasikan semangat PPI di sekolah kejuruan mereka. Untuk itulah kami dari Sanata Dharma membantu melayani mereka dengan menjadi narasumber dalam lokakarya dua hari yang mereka adakan di Griya Paseban, Semarang.

Tentu penekanan sekolah kejuruan berbeda dengan SMA, namun dari sisi semangat kiranya tidak terlalu berbeda. Artinya, mereka juga dapat menggunakan semangat PPI dalam pengelolaan SMK. Persoalannya adalah bagaimana semangat itu dapat diaplikasikan secara tepat sesuai dengan tujuan SMK dan kekhususannya?

Dengan latar belakang itulah maka dibuat lokakarya untuk para kepala sekolah dan staf SMKSMK yang dikelola oleh ASJI. Lokakarya ini terutama ingin memperkenalkan pengertian, konsep dasar, semangat dan nilai PPI kepada para kepala sekolah dan staf, sehingga mereka nantinya dapat membuat 
program bagaimana mengaplikasikan semangat PPI di SMK mereka masing-masing.

Yang diharapkan dari lokakarya ini adalah bahwa mereka mengerti isi utama PPI dan mereka dapat membuat program untuk diaplikasikan disekolah mereka. Oleh karena tujuannya lebih mengenalkan semangat PPI maka acara lokakarya yang utama adalah: (1) penjelasan oleh nara sumber tentang PPI;

(2) tanya jawab agar pengertiannya semakin mendalam; (3) pelatihan dalam kelompok kecil membuat program aplikasi PPI di sekolah; (4) presentasi beberapa hasil dan dibahas bersama.

Landasan teori. Secara teoretis, PPI (Paradigma Pedagogi Ignatian) adalah paradigma pendidikan yang didasarkan pada semangat Ignatian. Secara singkat dalam pedagogi ini siswa harus aktif belajar dan melakukan praktek agar menjadi cerdas dan terampil. Tanpa keatifan belajar sendiri, maka siswa tidak akan mengerti apapun. Guru lebih sebagai fasilitator yang mendorong siswa mau belajar aktif. Dalam proses ini relasi siswa dan guru adalah dialogis, saling membantu.

Dimanika PPI sendiri terdiri dari konteks, pengalaman, refleksi, aksi, dan evaluasi (Duminuco, 2000; NN, 1993; P3MP-LPM, 2012; Subagya, dkk., 2012; Suparno, 2015). Kalau pembelajaran ingin berhasil baik maka dinamika diatas tidak boleh diabaikan. Pendidik perlu mengerti konteks siswanya, menyediakan pengalaman dalam belajar, membantu siswa melakukan refleksi atas pengalamannya, kemudian memunculkan aksi yang ingin dilakukan. Pada akhirnya pendidik juga harus mengevaluasiapakah proses itu berjalan baik dan membantu siswa berkembang penuh.

Hasil yang diharapkan dalam PPI antara lain adalah siswa memperoleh 4C yaitu punya kompetensi tinggi (competence), punya suara hati (conscience), punya kepekaan pada orang lain (compassion), dan punya komitment yang tinggi dalam hidupnya (commitment).

Nilai dan semangat PPI diatas yang disampaikan kepada para peserta lokakarya dan sebagai tindak lanjut mereka membuat model RPP yang bergaya PPI untuk digunakan di sekolah mereka dan untuk membantu guru lain di sekolah mereka. Pada kelanjutannya diharapkan mereka di sekolah masingmasing mengembangkan nilai dan semangat PPI bagi kemajuan siswa.

\section{METODE}

Peserta lokakarya ini terdiri dari 42 orang yang mewakili 8 SMK (SMK Mikael, PIKA, Kanisius, Strada, dan Bina Teknik). Mereka terdiri dari kepala sekolah, pengurus standar mutu, kaprodi, dan tim penggerak PPR sekolah.

Metode yang digunakan dalam pengabdian masyarakat ini adalah sebagai berikut: (1) penjelasan tentang isi PPI oleh narasumber dan tanya jawab; (2) kerja dalam kelompok kecil membuat RPP bergaya PPI untuk digunakan di sekolah mereka; dan (3) presentasi hasil kerja kelompok dan tanggapan.

Dalam penjelasan narasumber menerangkan tentang isi penting dari PPI antara lain: asal usul PPI, semangat PPI, dinamika PPI, unsur yang penting dalam PPI, semangat yang perlu ditekankan dalam PPI, bagaimana membuat silabus dan RPP bergaya PPI, bagaimana hubungan SMK dengan DUDI (dunia usaha dan dunia industri) dan apa yang perlu ditekankan di SMK berkaitan dengan semangat PPI.

Dalam kelompok kecil peserta berkumpul menurut jenis SMK yang dikelola seperti SMK mesin, pertanian, sekretaris, perpajakan, animasi dll. Mereka membuat RPP bergaya PPI dengan mengambil salah satu mata pelajaran yang ada di SMK itu.

Setelah RPPnya selesai, beberapa wakit kelompok mempresentasikan hasil kerja kelompok mereka di di pleno dan ditanggapi oleh peserta serta narasumber.

Penjelasan narasumber dengan pendekatan partisipatif, banyak contoh real dan banyak juga masukan dari peserta dengan contoh-contoh dari lapangan. Narasumber juga membuat makalah yang dibagikan kepada peserta dan juga ppt yang dapat dicopy oleh peserta.

\section{HASIL DAN PEMBAHASAN}

\section{Semangat, keaktifan dan antusiasme peserta}

Para peserta kelihatan antusias dengan bahan yang dibahas. Hal ini ditunjukkan dengan banyaknya pertanyaan dan tanggapan dari mereka tentang isi dan semangat PPI. Juga dalam kesempatan tanya jawab mereka lebih banyak mengungkapkan gagasan mereka dan pandangan mereka tentang isi PPI yang didengar.

Mereka dalam kerja kelompok juga kelihatan bersemangat. Mereka aktif membuat RPP bergaya PPI. Diskusi mereka dalam kelompok juga kelihatan meriah. Ada beberapa yang memang sudah mengerti PPI sehingga dapat dengan mudah membantu teman lain dalam merumuskan gagasannya. Kebanyakan peserta membawa laptop sehingga pengerjaannya menjadi lebih mudah dan lancar. Beberapa kelompok sekaligus membuat PPT untuk persiapan presentasi.

Banyaknya pertanyaan dan juga sharing keadaan di kampus mereka masing-masing, menunjukkan bahwa mereka memang aktif dan 
sungguh ingin menghasilkan program yangdapat digunakan untuk sekolah mereka nantinya.

Dalam presentasi beberapa kelompok maju untuk menjelaskan RPP mereka yang bergaya PPI. Ada yang RPPnya lebih bergaya PPI dengan formalitasnya,ada yang lebih menekankansemangatnya tetapi bentuknya agak longgar. Namunyang menonjol adalah dalam proses pembelajarannya sekaligus dirumuskan dalam dinamikaPPI seperti konteks, pengalaman yang diberikan, refleksi, dan aksinya yang ingin dibuatnya.

Oleh karena SMKnya bermacam-macammaka contoh yang dipresentsikan juga diambil bermacammacam mata pelajaran sehingga setiap bidang terwakili. Yang diambil adalah dari RPP untuk matapelajaran akuntansi, mesin, pendidikan agama, teknik, keamanan kerja dll.

\section{Pengertian tentang PPI}

Dari hasil kerja dan presentasi peserta nampak bahwa mereka memahami isi, semangat dan nilai PPI yang digeluti. Mereka memahami dinamika PPI: konteks, pengalaman, refleksi, aksi, dan evaluasi. Mereka juga menyadari bahwa semangat PPI dalam pendidikan adalah: siswa harus aktif belajar dan menggali sendiri pengetahuan dan ketrampilan mereka. Tanpa keaktifan mengolah dan aktif belajar dan melakukan praktek sendiri mereka tidak akan punya kompetensi yang tinggi.

Mereka memahami dan menyadari bahwa relasi antara siswa dan guru adalah dialogis. Siswa harus aktif belajar dan melakukan praktek sedangkan guru membantu sebagai fasilitator. Tugas guru lebih sebagai pendorong dan penggelitik agar siswa aktif belajar.

Perhatian dan pendekatan pribadi guru pada siswa sangat dijunjung tinggi, cura personalis dikembangkan untuk membantu siswa makin semangat belajar.

Peserta menyadari bahwa semangat yang paling menonjol dalam PPI adalah bahwa siswadibantu menjadi pribadi yang utuh, yang berkembang secara menyeluruh baik dari sisi intelektual, ketrampilan, emosi, sosialitas, fisik, moral spiritual. Secara umum siswa dibantu menjadi pribadi yang cerdas dan terampil serta baik. Siswa dibantu menjadi pribadi yang berguna bagi orang lain, menjadi people for and with others.

Dengan seluruh pendekatan dan proses itu diharapkan siswa akan berkembang menjadi pribadi yang mempunyai kompetensi 4C: competence, conscience, compassion, dan commitment.
Peserta merasakan bahwa karena SMK ini sekolah kejuruan yang menekankan keterampilan, maka dalam kompetensi harus ditekankan dua hal yaitu kompetensi dalam pengetahuan dan keterampilan membuat sesuatu atau melakukan sesuatu. Siswa juga harus mempunyai suara hati yang kuat, tidak menipu dalam pembuatan alat dan ukurannya, jujur dalam pemilihan bahan dan mengerjakan pekerjaan. Mereka juga diharapkan punya kepekaan pada oranglain dan terutama nantinya pada mereka yanglemah. Dan tidak kalah penting adalah komitment pada pekerjaannya dan institusi dimana mereka bekerja. Jangan mudah pindah pekerjaan.

\section{Persoalan menonjol dalam tanya jawab}

Dalam kesempatan tanya jawab dan diskusi, ada 3 persoalan yang menonjol ditanyakan dan ditanggapi peserta yaitu: soal cura personalis, pendampingan guru, dan soal nilai $4 \mathrm{C}$.

Mereka mempersoalkan bagaimana sebagai guru atau pejabat menangani siswa-siswa yang nakal, yang semaunya, yang melanggar aturan sekolah, dan yang lemah. Bagaimana menangani siswa yang tawuran dan tidak jujur. Dari berbagai tanggapan akhirnya disepakati bahwa sebagai pendidik kita tetap harus mencintai dan memperhatikan mereka secara personal dengan persoalannya. Juga disadari bahwa penanganan siswa yang bermasalah bukan hanya tanggungjawab guru BK tetapi tanggungjawab semua guru.

Persoalan kedua yang juga banyak menerima tanggapan dari peserta adalah bagaimana mendampingi guru lain nantinya di sekolah dengan PPI. Beberapa merasa kurang kompeten untuk mengajari guru-guru. Dari pembahasan bersama akhirnya disadari bahwa mengajari guru lain tidak harus berceramah. Tetapi dapat melalui sharing yang dialami dan dibuat di lokakarya ini, mengajari membuat RPP bergaya PPI pelan-pelan, dan memberikan teladan dalam menyikapi dan mengajar siswa. Bahkan dapat juga belajar bersama di sekolah dengan mengundang guru yang telah ikut pelatihan untuk sharing.

Persoalan ketiga adalah soal nilai $4 \mathrm{C}$. Persoalan utama adalah nilai 4C mana yang harus ditekankan dalam membantu siswa sekolah kejuruan. Dalam pembahasan bersama disepakati bahwa untuk C1 kompetensi perlu ditekankan kemampuan siswa tentang ilmu yang dipelajari. Tetapi sekaligus juga siswa harus terampil dalam membuat dan menghasilkan sesuatu proyek. Misalnya, lulusan sungguh terampil membuat meja, membuat surat lamaran, membuat animasi. Lulusan kita harus unggul dalam ketrampilan ini! 
Untuk nilai C2 yaitu suara hati perlu ditekankan kesadaran siswa akan yang baik dan tidak baik, jujur dalam pengukuran dan pengerjaan proyek, tidak menipu bahan dan data. Untuk C3 yang perlu ditekankan adalah kepekaan siswa pada teman lain,mau kerjasama dengan teman lain baik dalam kelas dan laboratorium. Sedangkan untuk C4 commitment perlu ditekankan keseriusan siswa dalam melakukan pekerjaan, dalam berkegiatan, dan juga nanti kalau sudah kerja sungguh setia pada institusi tempat kerja.

Dalam mengembangkan 4C diatas juga disadari bersama bahwa nilai-nilai itu dapat lebih mudah tercapai bila siswa, kecuali belajar di kelas dan lab, juga melakukan kegiatan ekstrakurikuler dan bahkan live in di tempat yang berbeda. Kegiatan pengabdian masyarakat yang dilakukan sekolah dapat pula membantu terbenuknya nilai $4 \mathrm{C}$ dalam diri siswa.

\section{Hubungan SMK dengan DUDI dan KKNI}

Mengenai hubungan SMK dengan DUDI (dunia usaha dan dunia industri) dalam pembahasan disadari beberapa hal seperti: (1) Lulusan SMK diharapkan dapat bekerja di DUDIdengan baik. Agar tujuan ini tercapai maka perlu dibangun kerjasama SMK dengan DUDI yang akan menggunakan lulusan kita. Beberapa kerjasama yang perlu dibangun antara lain tentang:

- Menyesuaikan kurikulum SMK dengan kebutuhan DUDI;

- DUDI membantu perubahan kurikulum SMK agar tepat guna;

- Pelatihan dan magang siswa di DUDI, sehingga siswa tahu betul bagaimana bekerja yang sebenarnya;

- Kerelaan DUDI membantu siswa SMK untuk pelatihan dan belajar praktek.

- Perjumpaan staf SMK dengan DUDI untuk menyatukan kepentingan dan peningkatan pendidikan yang tepat guna. Perjumpaan antar mereka yang rutin akan membuat saling mengerti kebutuhan masing-masing dan menghilangkan halangan yang sering terjadi.

Sedangkan tentang KKNI yang perlu mendapatkan tekanan di SMK adalah kemampuan berbahasa asing; penggunaan jaringan internet, komputer; integritas, kejujuran; serta keberanian komunikasi. Beberapa kemampuan ini membantu lulusan untuk dapat berkomunikasi lebih luas dan bersaing dalam pasar bebas Asia (MEA).

\section{Analisis}

Dari hasil presentasi RPP bergaya PPI yang dibuat para peserta dan tanggapan mereka dalam kesempatan tanya jawab, dapatlah dikatakan bahwa mereka sungguh mengerti isi pokok, semangat, dinamika PPI. Mereka menguasai pengertian tentang PPI dan juga mengerti bagaimanasemangat PPI itu mau diaplikasikan di sekolah mereka.

Mereka masing-msing dapat merencanakan pembelajaran bergaya PPI dengan pendekatan dan contoh-contoh konteks siswa di sekolah mereka yang real. Dari sini mereka bukan banya tahu, tetapi mereka mampu mengaplikasikan pengertian PPI mereka dalam merencanakan pembelajaran tentang mata pelajaran mereka sendiri. Hal ini nampak dari contoh-contoh yang mereka ambil dalam RPP.

Melihat dan mengalamisemangat mereka yang besar kiranya dapat diyakini bahwa

mereka nantinya akan mengaplikasikan semangat dan dinamika PPI di sekolah mereka. Maka ada harapan bahwa semangat dan pendekatan PPI ini pelan-pelan mulai tumbuh di lingkungan SMK mereka.

Kendala yang kiranya sudah nampak adalah keinginan mereka agar PPI cepat terlaksana di sekolah mereka, terjadi diantara para guru dan siswa. Keinginan yang menggebu-gebu ini kiranya perlu diawasi, sehingga mereka tidak terlalu cepat ingin mengubah segalanya. Proses PPI membutuhkan waktu yang lama dan kesabaran serta daya tahan dalam mengaplikasikan. Ketergesaan akan menjadikan mereka nanti mudah frustasi bila ternyata tidak jalan.

Yang masih belum dibahas secara mendalam adalah bagaimana agar semangat PPI itu terjadi secara menyeluruh di seluruh sekolah. Artinya, semangat itu juga harus dilakukan oleh semua anggota civitas akademika sekolah yaitu: kepala sekolah, guru, tenaga administrasi, dan siswa. Dalam keseluruhan itu maka semangat PPI itu akan mudah terlaksana. Disinimereka masih perlu membahas dan membicarkan lebih mendalam kesembalinya mereka ke kampus masingmasing.

Para peserta disemangati oleh pengurus ASJI untuk membuat buku pedoman PPI bagi pengelolaan sekolah SMK seperti kolese Jesuit yang lain. Tentu ide membuat buku pedoman ini sangat bagus, dan akan menjadi pegangan tertulis yang mudah diikuti. Namun perlu disadari bahwa pembuatan buku pedoman tidaklah instant tetapi mereka perlu mendalami isi PPI secara lebih mendalam dulu. Sebagai perbandingan Kolese Jesuit yang lain (SMP dan SMA) membutuhkanwaktu lebih dari 2 tahun untuk menghasilkan buku pedoman yang sekarang ini dipublikasikan.

Dalam konteks membuat buku pedoman kiranya lokakarya ini juga akan membantu mereka untuk menentukan nilai apa yang khas bagi SMK. 
Dalam diskusi tentang dinamika PPI hal yang sangat penting ditekankan di SMK ada dua hal yang menonjol yaitu kebiasaan refleksi dan pemberian pengalaman. Refleksi sangat penting untuk siswa SMK agar siswa tidak terbentuk menjadi robot. Robot yang berarti pandai membuat sesuatu barang tetapi tidak mengerti apa kegunaannya dan terutama kegunaan bagi manusia yang lebih utuh. Banyak siswa SMK dididik menjadi tenaga teknis yang terampil membuat macammacam barang tetapi tidak pandai refleksi. Bahkan tidak tahu mengapa barang ini dibentuk begitu atau begini. Maka guru PPI harus membantu siswa berefleksi. Siswa dibantu menggunakan otak dan hati.

Yang kedua adalah pemberian pengalaman. Sebenarnya di SMK siswa sudah lebih banyak diberi pengalaman, terutama pengalaman laboratorium dalam membuat suatu barang atau proyek. Namun masih perlu ditambahkan yaitu pengalaman diluar kampus, pengalaman berjumpa dengan manusia dan lingkungannya. Dalam mensukseskan PPI siswa perlu sering dihadapkan pada pengalaman hidup real masyarakat. Mereka perlu live in di daerah yang dapat menantang kemanusiaan mereka. Pengalaman live in dan kemasyarakatan perlu dipikirkan dan direncanakan secara jelas sehingga dapat selalu dilakukan dalam tahun-tahun selanjutnya.

\section{KESIMPULAN DAN SARAN}

Secara keseluruhan pelaksanaan program lokakarya bagi kepala sekolah dan staf SMK ASJI ini menghasilkan beberapa hal sebagai berikut:

(1) Peserta mengerti isi pokok, semangat, nilai, dimanika PPI sehingga dapat mengaplikasikan di sekolah mereka;

(2) Peserta dapat membuat RPP yang bergaya PPI yang nantinya dapat ditularkan kepada guru-guru lain di sekolah mereka, sehingga guru-guru dapat menjalankan semangat PPI dalampengajaran mereka;
(3) Peserta dapat merumuskan kekhasan semangat PPI di SMK; dan

(4) Peserta menyadari pentingnya membangun relasi dan kerjasama dengan dunia usaha dan industri agar para lulusan nantinya siap bekerja di bidang industri dan usaha. Selain itu peserta juga menjadari pentingya siswa mengembangkan kemampuan berbahasa asing, kerjasama, komunikasi, dan menggunakan internet demi bisa bersaing di pasar bebas MEA kedepan.

Dari pelaksanaan program lokakarya ini ada beberapa saran yang perlu diperhatikan yaitu:

(1) Sebaiknya dibuat pelatihan PPI sendiri di sekolah masing-masing sehingga seluruh warga sekolah serentak belajar bersama, dan memudahkan dalam mengaplikasikan bersama semangat PPI diseluruh sekolah.

(2) Sekolah yang sudah punya program PPI secara mantap agar rela menularkankepada sekolah lain;

(3) Rencana buku pedoman dilakukan pelan-pelan dengan pembagian tugas tiap sekolah secara jelas.

\section{DAFTAR PUSTAKA}

Duminuco, S.J. (editor). 2000. The Jesuit Ratio Studiorum $-400^{\text {th }}$ Anniversary Perspectives. NY: Fordham Univ.Press.

Kolvenbach, S.J., Peter Hans. Pedagogi Ignatian masa kini. Konteks: Humanisme Kristiani zaman sekarang. Terjemahan J. Drost, S.J.

NN. 1985. The Characteristic of Jesuit Education. London: Jesuit Institute.

NN. 1993.Ignatian Pedagogy: A Practical Approach. London: Jesuit Institute.

P3MP-LPM. 2012.Pedoman Model Pembelajaran Berbasis Pedagogi Ignatian. 2012. Yogyakarta: USD.

Subagya, S.J., dkk. 2012. Paradigma Pedagogi Reflektif. Edisi Revisi. Yogyakarta: Kanisius.

Suparno, Paul. 2015. Pembelajaran di Perguruan Tinggi Bergaya PPR. Yogyakarta: USD. 